searched for tubercle bacilli, but none were found, and the histology did not suggest tuberculous disease. Many investigators have attempted without success to find a bacterial origin for this disease, but Dr. A. G. Gibson ${ }^{1}$ of Oxford has described and figured a streptothrix found by him in different cases of splenomegaly, including cases of Banti's disease. We have examined numerous sections of the spleen and haemolymph glands, employing the Wheal ${ }^{2}$ and Chown method of staining, as recommended by Dr. Gibson, for the identification of the organism, but have not met with a streptothrix in any of the tissues examined. We have had more recently the opportunity of examining aĩother spleen successfully removed from a case of Banti's disease by Mr. Howell at the Cheltenham Hospital. Portions of this spleen were placed in culture media immediately after excision, but all the cultures remained sterile. Sections of the spleen were searched for a streptothrix, with negative results.

Considerable controversy lias talien place as to whether haemolymph glands are actually separate and distinct organs sui generis, or whether they are to be regarded as lymphatic glands into the lymph paths of which blood has come by liaemorrhage, diapedesis, or throngh the convection of extravasated blood from other areas by the lymph channels.

Professor Warthin of Michigan has made a special study of the subject for a considerable number of years and has contributed largely to its literature. He is firmly convinced that the hacmolymph node is an organ sui yeneris, and expresses the following opinions: ${ }^{3}$ "I beliere that these minute haemal organs possess distinct functions, and that specific as well as general pathological changes occni in them." "It would therefore appear that the destructive influences of chronic intoxications and infections, as well as altered conditions of the blood, affect the spleen and bone marrow earlier and to a greater degree than they do the haemolymph nodes. The latter may be interpreted consequently as reserve haemal organs. In conclusion livperplasia is the most common specific pathological change in the haemolymph nodes, and this hyperplasia may be of four types-lymphoid, endothelial, myeloid, or fibroid, or a combination of these." Saltykow champions the opposite opinion and considers that the presence of the red blood corpuscles stimulates the endotholial cells of the lymphatic glands to intense phagocytic activity. The opposing views are clearly stated by 1)r. Dayton ${ }^{4}$ of New York. From the study of enlarged haemolymph glands occurring in a case of exophthalmic goitre, Professor Lorrain Smith ${ }^{5}$ summed up as follows: "The general conclusion to which the study of this case leads us is that the haemolymph gland is in one form at least nothing else than an ordinary lymph gland into the sinuses of which blood has found its way. How far this conclusion is valic for other cases it is at present impossible to say."

In the case here recorded we may say:

1. The lymphatic glands in the abdomen have undergone a hyperplasia of their histological elements similar to what has occurred in the spleen.

2. Blood is present in the lymph sinuses of these lymphatic glands to a variable extent, and the amount of blood present bears no relation to the hypertropliy of the endothelial cells or fibrous tissue of the gland.

3. The haemorrhage into the mesentery and the blood in the ascitic fluid suggest that the blood corpuscles in the sinuses of the lymph glands have been transferred from thence via the ordinary lymph paths. It seems, however more probable to us that these haemolymph glands represent blood organs sui generis in which the same pathological changes have occurred as in the other blood orgav, the spleen, than that the great hyperplasia of the endothelial cells and fibrons tissue is simply the result of the presence of red corpuscles in the lymph paths of normal yomphatic glands.

A small angioma was present on the anterior surface of the liver. Areas of fibrosis and collections of small round cells were present about the portal systems, and to a less extent in the intercellular tissue. A certain amount of fatty infiltration was present, more marked near the angioma. The capillaries were distended with blocd. 'The pancreas appeared perfectly normal.

The sections of the lungs showed the presence of emplysema.

$\boldsymbol{\Lambda}$ section was made through the origin of the portal vein, at the junction of the mesenteric and splenic veins, as the site most likely to be diseased. 'The walls of the vein were quite liealthy. A portion of the splenic artery exhibited early atheroma.

Sections of the suprarenal glands exhibited no abnormality.

The lidneys exhibited the histological changes of chronic interstitial nephritis, the left kidney being. considerably more fibrosed than the right.

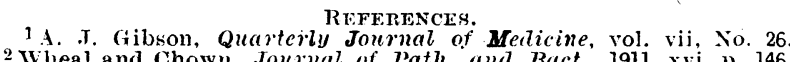

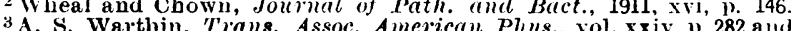
p. 289. W Hughes Dayton, Amer. Jour vol. exrvii, 1. 448. है, Lorrain Sinith, Dreschfeld Nemorial Volmue, 1. 208.

\section{EXOPHTHALMIC GOITRE.}

AN ABSTRACT OF THE RESULT'S OBTAINED FROM THE INVESTIGATION OF 93 CASES.

BY HELEN M. GUPNEY, M.D.,

MUDICIT, RFG ASSISTANT PHYSICIAN, SICK CHILDIREN'S HOSPITAI, DEWUASTLE-OS-TYNL:

Tне 93 cases of exophthalmic goitre investigated were all in-patients of the Royal Victoria Intirmary between 1903 and 1914. They were examined with especial reference to the etiology and prognosis, and the following conclusions were arrived at:

$$
\text { A.--Etiologis. }
$$

1. Heredily.--In 10.7 per cent. of these patients near relatives had suffered from simple goitre; in 3 per cent. from exophthalmic goitre. In one case a mother and six daughters all had simple goitres, which in two daughter's appeared accompanied by exophthalmos.

2. Sc..-92.5 per cent. were females.

3. Age at Onset. This varied from early childhood to 50 year's.

$$
\begin{aligned}
& \text { In } 4 \text { patients it appeared before } 10 \text { years of age. } \\
& \text { In } 28 \text {,", between } 10 \text { and } 20 \text { veaiss of age. } \\
& \text { In } 35,, \quad,, \quad, \quad 20 \text { and } 30 \text { " , } \\
& \text { In } 14 \quad, \quad, \quad, \quad, \quad, \quad 30 \text { and } 40
\end{aligned}
$$

4. Duration of Illness.--This included all periods fiom a few weeks to twenty years.

5. History.--(a) Antecedents : 39 per cent. gave histories indicating some preceding throat trouble and suggesting the possibility of infection through the tonsils.

(b) Exciting cause: Emotional in 20 per cent.; disturbance of generative organs in 9 per cent.; other illnesses in 8 per cent.; operation in 3 per cent.

B.--Developyent of Syiptoms and Sigis.

(a) Primary.-Goitre appeared first in 62 per cent., exophthalmos in 21 per cent. In those cases which followed emotional disturbance exophtlialmos was the first symptom in 80 per cent. It should be noted that in almost every case there was a vague history of nervonsness, as shown by palpitation and various subjective phenomena, before any local signs appeared.

(b) Secondary.-In addition to the cardinal signs of exophthalmic goitre, various secondary points were investigated.

Contrary to expectation, the prognosis was not markedly influenced by the presence of hallucinations (7 cases), organic or functional disturbances of the cardio-vascular system (in 43 per cent.), severe diarrhoea (which occurred in 36 per cent., of which number 20 per cent. died), or considerable disturbance of the integumentary system.

Bronchitis and other diseases of the respiratory system were found in 11 per cent., and of this number 80 per cent. died.

Amenorrhoea occurred in 15 per cent. In some cases it appeared before the disease and improved when the goitre developed. In 6 cases miscarriages preceded the disease. The effect of menstruation on exophthalmic goitre is not constant; sometimes the goitre diminishes in size, and sometimes it is increased during the period.

\section{C.-Prognosis.}

The prognosis is markedly influenced by:

1. The Age of the Patient at the Onset.-The death-rate is 25 per cent. in cases beginning between 10 and 15 years 
of age, and increases gradually to 44.5 per cent. in cases beginning after 45 .

2. The Duration of the Illness before Treatment.In cases coming into hospital who have been ill under one year the death-rate was 35 per cent.; between one and two years, 75 per cent. The rate falls after the fourth year, as after that length of time the clisease may be regarded as chronic and symptoms are always less acute.

In addition to these points, early development of rery acute symptoms, such as diarrhoea and tachycardia, adds to the gravity of the prognosis.

\section{D.-Course.}

Treatment consisted in rest in bed in all cases. Tarious drugs were used according to the most prominent symptoms in each case.

Up to 1908 most patients were treated by the electric battery, and more recently by $x$ rays. There was considerable temporary improvement, but possibly no more than by other means. It is too early to speals of the permanency of the improvement under $x$ rays.

Rodagen, thyroidectin, antithyroid serum, and antithyroidin have all been used, and while each has been successful in some cases, none has had a gencially good enough result to encourage its universal use.

Of 93 cases 64 have been traced at periods rarving from six months up to ten years since leaving the infirmary.

18.75 per cent. declare themselves quite well and able to work.

20.3 per cent. are definitely improved.

20.3 per cent. are much the same.

4.75 per cent have developed myxoedema.

6.25 per cent. were transferred to surgical wards.

29.7 per cent. are dead $(6.25$ per cent. while under treatment in the infirmary).

Many patients who are entirely cured of all disturbing syrnptoms and who are otherwise absolutely well, retain some permanent enlargement of the thyroid.

I am indebted to the past and present honorary phy sicians of the Royal Victoria Infirmary for permission to make use of their cases and notes, and especially to Professor Muray, of Manchester (late of Newcastle), who has allowed me to use many particular's of cases treated by lim.

\section{TIIE CAUSE OF APPENDICITIS.}

BY

BASIL HCGHES, M.B., B.C.CANT.ı., B.SC.ToNd., F.R.C.S.ENG.

BradFond; Liegtexant R.A.M.C., Ist West Rining Fit.d AMBULANCE.

THE question as to what brings about the pathological conditions in an appendix which give rise to appendicitis has been widely discussed from several standpoints.

I venture to suggest a theory, which $I$ think is new, as in the literature I can find no allusion to it.

All cases of appendicitis are in the first place due to a mechanical cause, and this consists in a rotation of the or'gan about its meso-appendix.

I consider the acute inflammatory process. whether it go on to abscess formation or not, to be purely secondary to this rotation.

'This is assumed for the following reasons:

(a) The valve of Gerlach is by no means a reliable valve.

(b) In almost all quiescent appenclices, which hare never given rise to any symptoms and which hare been remored during pelvic operations, I hare always becn able to culture intestinal orgavisms from thiei cavities--that is, the normal contents of the appendix are not sterile.

What Happens when the Appendix Rotutes?

Anatomically the appendix is quite frec to rotate on its mesentery, and as to what actually talies place will depend upon the degree of rotation.

If the rotation be complete, then the condition is similar to that of an ovarian cyst completely twisted about its pedicle. The venous return is stopped. but the arterial supply is not wholly cut off. We therefore get initially a state of acute congestion. Infection superrenes on this damaged organ, and gangrene with abscess are the usual termination.

This type of case-is familiar in that its onset is sudden, the pain is acute, the patient romits, which romiting I take to be purely reflex; in fact, the initial symptoms are similar to those of a twisted orarian cyst in the female.

In less acute cases the rotation is not complete, and the venous return is not wholly cut off. These patients, if put to bed and kept quiet, invariably get orer their first attack.

The symptoms at the onset are not so acute; there may be vomiting, certainly some pain, there is tenderness ore McBurney's point, but all this usually subsides.

These patients, if operated upon in the acute stage, har', always in my experience shown some degree of rotatici of the appendix. The organ is stiff and congested, an $I$ there are subserous haemorrhages.

Similar cases operated upon in the quiescent periocis have shown the familiar link in the oroan, and if this be carefully examined it will be found to be produced by a partial rotation of the organ about its mesentery.

The third type of case is that where there is a loig meso-appendix and the organ from mechanical conditicns I shall mention directly is rotating on its mesentery and recovering itself.

This type of appendix has, in my experience, invariably been the one that has giren rise to gastric symptoms, which Sir Berkeley Moynihan has called "appendix dyspepsia." My experience in this type of appenclix is interesting, and I hope others will hare noticed this. In four cases I performed a laparotomy with the purpose of performing gastro-enterostomy. In all four cases the stomach was dilated, but no ulcer or disease was to be found, though the symptoms were those of gastric ulcer. In these cases a very movable caecum was present with a long appendix suspended by a long meso-appendix; there had been marked constipation in all fonr cases. I did nothing further than remove the appendix, and the result in all four cases was highly satisfactory, as all the gastric symptoms disappeared and the bowels moved regularly.

It is well known that abdominal operations in which any extensive handling of the mesentery is necessitated give rise in the patient sometimes to acnte dilatation of the stomach. If, then, there is anything present which is constantly tugging on the mesentery orer any length of time, it is quite reasonable to suppose that the stomach will react in the same way, but in a more chronic fashion. The process, it is fairly agreed, is reflex, and I think, seeing that these cases were cured, we have in this the explanation of the so-called "appendix dyspepsia."

Surgeons will, I think, recognize how difficult it often is to trace an appendix and its whereabonts when it has gone on to a condition of abscess formation, and those who do not believe in amputation of the appendix at these times, but who are content to find the abscess and drain it, will not have, perhaps, the opportunity of bearing me out; but they will surely find, if they go further with the operation of removing it, that the difficulty lies in the fact that the appendix has completely rotated on its own mesentery, and has become bound down, and there often appears to be no meso-appendix

This, however, is a fallacy, the meso-appendix being shortened by the twist.

What, then, causes this Rolation?

The clief factor's which bring this rotation about are :

(a) A morable loaded caecum

(b) Loss of tone in the abdominal muscles.

The most important is the second of these two factors, for on it in some measure depends the fir'st.

A loaded movable caecum is free to more in three ways :

1. It can descend

2. It can move laterally.

3. It can expand forwards.

These three conditions are just those required for a rotation of the appendix on its meso-appendix, and the only condition that can bring these about is constipation.

Loss of tone in the abdominal muscles is one of the commonest canses of constipation and later of some amount of enteroptosis. 